Article

\title{
Neighborhood Planning for a Divided City: The Case of Beirut
}

\author{
David Aouad \\ Department of Architecture and Interior Design, Lebanese American University, Lebanon; david.awad@lau.edu.Ib
}

Submitted: 14 July 2021 | Accepted: 26 October 2021 | Published: 23 February 2022

\begin{abstract}
This article discusses planning within Municipal Beirut, Lebanon, while focusing on the specific context of divided cities and societies, proposing a series of recommendations based on socio-economic and political science and planning theory to understand such contexts. It explores the case of Municipal Beirut that has undergone a devastating blast on August 4th, 2020, and left thousands of households in critical condition by leaving an already shattered sectarian city/society with an unforeseen planning future. By examining successful examples or frameworks in other cities and similar-context cities in history with urban/social shocks, evaluating current planning initiatives, and analyzing the case study of the recent Beirut Urban Declaration report, this article investigates neighborhood planning as a flexible framework that one must undertake to provide the divided city of Beirut a healthy and sustainable development. It argues that difference and diversity are a noteworthy feature of the city of Beirut and its society and should hence be incorporated in any planning approach even if the consequences on the ground may differ. Considering that planning could change the spatial, socio-economic, and political dimensions of a defined urban space, this article explores which of these dimensions can be used to intensify or lessen contestations over space in Beirut under the current sectarian culture reflected in both social and spatial realms. In the wake of the blast and amid all these divisions, this article will show that neighborhood planning stands out as a flexible and sustainable solution. By establishing a spatially targeted program, introducing innovative tools for neighborhood planning and management, and initiating a small-scale governance structure, neighborhood planning will create an intermediate level between the municipality, citizens, and other local actors, enhancing its social capital and leading eventually to an undivided planning strategy at a national and city scale.
\end{abstract}

\section{Keywords}

Beirut; Beirut Urban Declaration; divided city; divided society; intra-urban inequalities; neighborhood planning; sustainable post-war recovery

\section{Issue}

This article is part of the issue "Urbanisation, Crisis, and Resilience: The Multiple Dimensions of Urban Transformation in Beirut, Lebanon" edited by Liliane Buccianti-Barakat (Saint Joseph University) and Markus Hesse (University of Luxembourg).

(C) 2022 by the author(s); licensee Cogitatio (Lisbon, Portugal). This article is licensed under a Creative Commons Attribution 4.0 International License (CC BY).

\section{Introduction}

The Beirut Port explosion on August 4th, 2020, was a watershed event in the history of Lebanon and the capital city of Beirut. Large sections of the Beirut Port and its infrastructure were destroyed, including the silos that contained most of Beirut's grain reserves. The blast also caused damage to several nearby residential neighborhoods and affected five major hospitals. Several governmental buildings were also damaged. It is a catastrophe that affected the neighborhoods of Medawar, Karantina,
Al-Badawi, Mar Mikhael, Rmeil, Gemayzeh, St. Nicolas, and extended to Burj Hammoud, Ashrafieh, Bashoura, and Zuqaq El Blat (Figure 1). It reached the other neighborhoods of the city leaving behind more than 200 people dead and thousands wounded; in addition, it has damaged more than 6,000 buildings causing complete or partial destruction (Table 1), and the displacement of tens of thousands of residents of the area. This catastrophic event has mobilized the efforts of many professionals, scholars, private and public institutions, as well as NGOs. Amid a wave of local and international 
organizations providing help and assistance for many, within the current turbulent and unstable socio-political landscape brought about by the 4th of August events, Beirut is impoverished by a series of overlapping poor management where sectarianism has emerged as a crucial mobilizing agent in the struggle for urban reform or preservation.

Since August 4th, and for many local and international professionals, scholars, and opportunistic developers, the impact of the Beirut Port blast offered an opportunity to appraise the relationship between many critical aspects of the city planning such as the relationship of the city to its suburbs, waterfront, and city center (Aouad \& Kaloustian, 2021). The lack of local planning and cross sectorial master plans have generated clusters within the city; the city center has become one of those clusters, disconnected from its waterfront. Moreover, the contrasting situation between the strive to preserve the heritage and the complexity of its urban development have led to the increased urbanization and city growth; the infrastructure and service systems have, over the years, become increasingly deficient. The lack of public spaces impacts on urban climate, the urban divide, and inequality have only grown deeper since the blast, causing a combined and adverse impact on the quality of city life (Aouad \& Kaloustian, 2021).
While this article proposes community-driven neighborhood planning as a method to guide post-war recovery in divided neighborhoods, the key question asked is not whether these methods will mitigate divisions among neighborhoods as a result of these interventions, as this is a different topic, but rather how the devastated neighborhoods should get organized to improve their quality of life within a clustered and divided city. This article first provides a short assessment of the divided city modelits undertaking, enactment, and drawbacks. It then provides examples of Beirut's past and current city policies, schemes, and approaches, and explores the evolution, objectives, and goals of its current and future urban trends. Through case studies and literature-based evidence, this article argues that the urban planning methods used prior to the blast, and possibly after, have led to the emergence of intra-urban inequalities in the affected areas and generated divisions as well as civic disinterest.

One initiative will be singled out in the next section, not because it provides a sustainable solution, but because it epitomizes a customary way of reshaping urban environments towards an undivided city through its attempt at bottom-up neighborhood planning: the Beirut Urban Declaration (BUD). Section 3 will describe and analyze the different recommendations provided by the BUD team and will critically highlight the different faux-pas

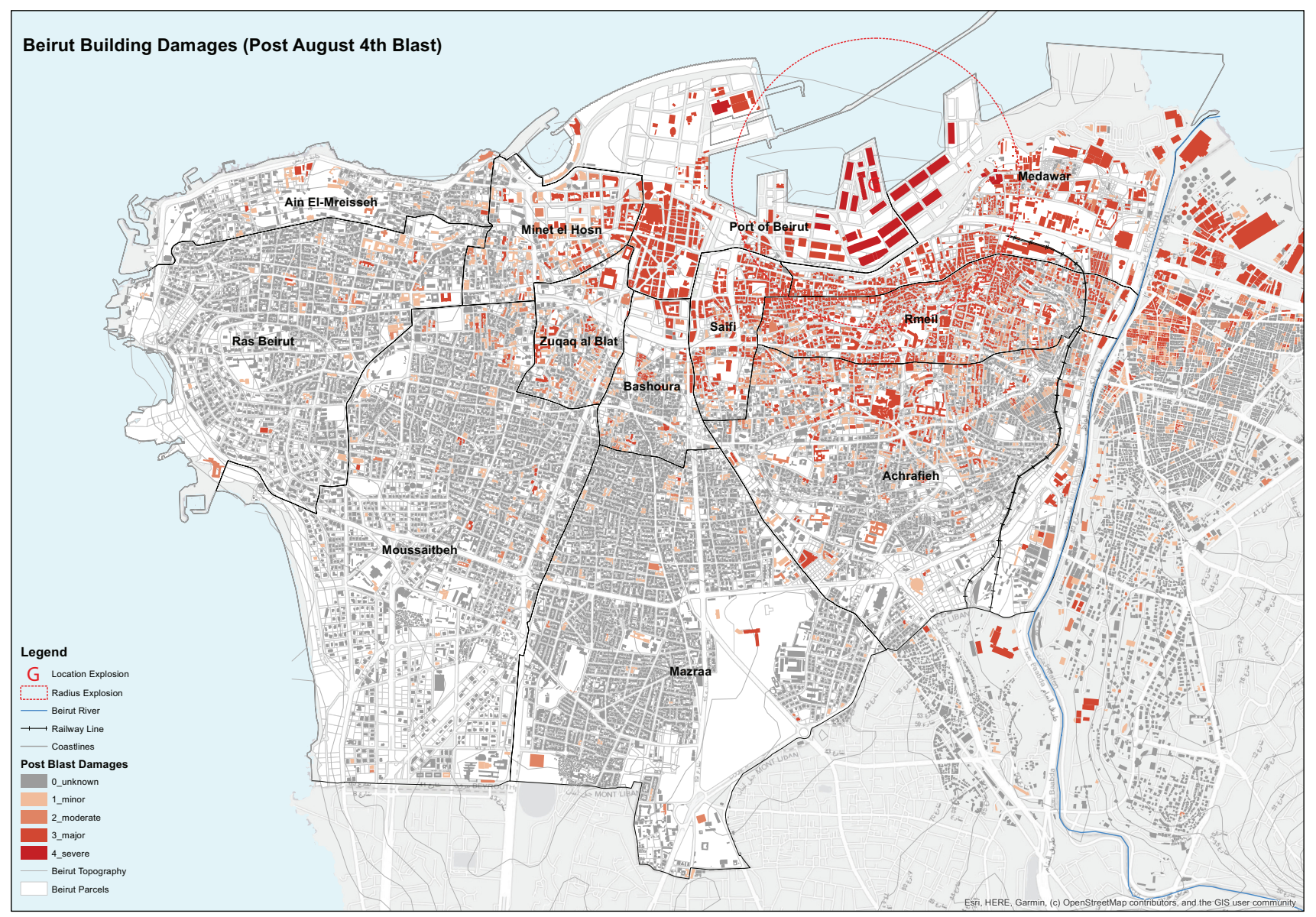

Figure 1. Post-blast building damages in Beirut. Source: Author's work based on the Order of Engineers and Architects (2020). 
Table 1. Damaged buildings in Beirut from August 4th blast.

\begin{tabular}{lcr}
\hline Damage Level & No. & $\%$ \\
\hline Minor & 2,236 & 33.81 \\
Moderate & 1,364 & 20.62 \\
Major & 2,981 & 45.08 \\
Severe & 31 & 0.47 \\
\hline
\end{tabular}

Note: Surveyed from a total of 6,612 damaged buildings. Source: Order of Engineers and Architects (2020).

and missed opportunities. In response to the particular and failing urbanism of Beirut (political, social, spatial, anthropological, etc.). Section 4 will present a literature review on different neighborhood planning approaches within the same context of divided cities and introduce small-scale governance structure and innovative planning tools, and community-based neighborhood planning as a method to create an intermediate level between the different stakeholders (municipality, citizens, and other local actors) through enhancing its social capital and eventually leading to an undivided planning strategy at a city/national scale. Section 4 will go through the different recommendations for neighborhood planning in divided cities and overlay them with the BUD recommendations in order to draw conclusions in the final section.

\section{Divided and Polarized Cities: Towards an Understanding of Intra-Urban Inequalities}

In recent years, scholars, planners, developers, and policy makers alike have given particular attention to the concept of divided cities as a prolific model for understanding divisions related to social, cultural, economic, and political divisions. The divided city is a physical crisis nested within a political crisis (Calame \& Charlesworth, 2009); the physical nature of the city stems from its local spatial, psychological, and economic dynamics that operate semi-autonomously and differentiates it from larger political milieus. In most cases, a divided society will eventually generate a divided urban space, hence a clear interrelation is established between a divided society and a divided city (van Kempen, 2007). It is a matter of the connection between social ramification and social inequality on the one hand and spatial segregation on the other. Inequalities can aggravate inconsistencies and abandon society's most vulnerable members. Bollens (2007) outlines the prospective role of cities in their ability to reunite divided societies, where he argues that urban planning could play a constructive role in reuniting divided cities:

Division-whether it is physical or psychologicalis an extremely difficult emotion that spawns hatred, grief, denial, depression, and forgiveness [...]. Characterized by potent political, spatial, and social-psychological contestation [cities] are usefully described as "polarized." Where almost all cities are divided socioeconomically and culturally, polarized cities contain a depth of antagonism and opposition beyond what the word divided connotes. (Bollens, 2012, pp. 16-17)

\subsection{Dividing Lines and Mental Frontiers}

In extremely divided cities, the most notable processes behind division are political and ideological oppressions such as wars, as well as divide-and-rule and exit strategies of the colonizers (Caner \& Bölen, 2016). This challenging situation is well reflected in questions of identity, national sovereignty, territory, culture, and religion. Coupled with multiple socio-economic differences cities can often be divided, and rather than providing economic chance to citizens with different milieus and skills, specific groups find themselves often isolated in specific neighborhoods facing limitations to access opportunities, amenities, and services. While the OECD report on divided cities and understanding intra-urban inequalities considers the multiple dimensions of inequality, including income levels, migration, and accessibility, it argues that there is a strong correlation between spatial inequalities and segregation in cities (OECD, 2018).

Spatial inequality in dwelling conditions or accessibility to social and physical infrastructure often materialize in urban areas of developing cities, affecting the quality-of-life of those living in these areas (Martínez, 2009). To narrow the increasing gap between better-off and worse-off neighborhoods, policy makers are trying to compensate for discrepancies and target these underprivileged areas. Moreover, the specific morphology of cities, their history, their geographical characteristics, and the extent of inequality in a society are just a few of the contingencies that determine the present and future of divided cities (van Kempen, 2007). From such contingencies emerge divisions; if not recognized, it is impossible to draw a clear roadmap for the elaboration of a sustainable planning strategy. Although the results on the ground can work out very differently for each place, it will be crucial to look at divided cities keeping in mind individual preferences, individual constraints, and opportunities.

\subsection{Damaged Identities and Broken Histories: Beirut, a Divided City/Society}

Beirut is a divided city: Although there was a clear boundary during the civil war (Green Line), dividing the 
Christian East and the Muslim West, today, hundreds of such lines dissect the city (Bou Akar, 2018); urban fault-lines, physical markers, or invisible lines shape behaviours and merge identities with territories (Bollens, 2012). However, while these dividing lines have been officially removed, the climate of divide created by these boundaries is still heavily anchored in the mental maps of inhabitants. These mental maps, whether through psychological fractures, sectarian turbulence, racial turmoil, or political obstacles, tend to emerge more often than in the original times of civil conflict, providing profound insights into the fear, separation, violence, and alienation that run through most large metropolises (Calame \& Charlesworth, 2009).

As a result of these invisible markers, Caner and Bölen (2016) outline the production of functional, structural, socio-economic, and physical consequences, all unique and non-negligible (Table 2).

Divided cities are shaped by social, political, and spatial dynamics, speeding the production of conflict and violence. In the case of Beirut, these dynamics are portrayed in four aspects: (a) the urban differentials in the settlement pattern of sectarian groups or communities and their outcome in terms of the relationship between the old and new urbanities; (b) the inter-communal social relations and the role of the urban condition in shaping social interactions between communities; (c) the influence of the urban condition on shaping the political process and politicization of communities; and (d) the outcomes of conflict and violence on re-shaping the city and its milieus (Yassin, 2008). While neighborhoods reproduce poverty, displacement, and urban violence (Bou Akar, 2018), Beirut has always seen separate enclaves co-existing within its neighborhoods (Figure 2), harnessing sectarian consciousness among its residents
(Silver, 2010). The term "urbicide" (Fregonese, 2009) has been used critically to describe the role that built environment played in defining the tactical maneuvers of rival militias during the 1975-1976 civil war. Militias used several means to re-organize the urban space and territory according to the unfolding political, sectarian, and military realities. Acting as urban designers, militia leaders redesigned the city and its context, transforming commercial and civic buildings to produce a new spatial order aimed largely at reaffirming the new social and political orders under their control (Yassin, 2012). Neighborhoods were isolated by checkpoints; the city was changing its materiality due to its conflicts (Fregonese, 2009). In 1990, when the second civil war finally ended, division still lingered in the city; clashes between different religious groups resurfaced, and planning remained indifferent to this reality (Davie, 1994). However, the infamous Green Line, that once clearly divided the city in two (Yassin, 2012), has given way, throughout the years, to a more complex and intertwined division scheme. As Figure 2 shows, and based on Table 2, several clusters have been identified within the city: (a) the city center; (b) the educational hubs of the American University of Beirut and the Lebanese American University; (c) the camps (including but not limited to Mar Elias, Karm El-Zeytoun, Nour Hajin, and Basta); (d) the isolated port area; (e) Karantina and Horsh Beirut (Pine Forest); and ( $f$ ) the duplicated commercial hubs of $A B C$ Verdun and Achrafieh and the stretches of Mar Mikhael and Hamra streets. The emergence of these clusters shows how stakeholders have been approaching planning throughout the years, using strategies that selectively "whiten" certain areas at the expense of others (Avni \& Yiftachel, 2014), pushing for anesthetization, privatization, and gentrification.

Table 2. Urban consequences of the divisions in Beirut.

\begin{tabular}{ll}
\hline Type & Consequences \\
\hline Functional Consequences & Decline in central functions of the urban core \\
& Segregation of residential areas, ethnic enclaves \\
& Bipolarization of commercial areas \\
& Fading primacy of capital city administrative functions \\
& Duplication of urban functions (transportation, services, etc.) \\
& Change of functions in urban space \\
& Change in urban development patterns \\
Structural Consequences & Road-dominated environment and proliferation of cul-de-sacs \\
& Presence of frontier landscape \\
& Proliferation of vacant land \\
& Deterioration of buildings \\
Socio-Economic Consequences & Division of everyday artefacts \\
& Economic depression and chronic fear \\
& Population exchange, homogeneous zones \\
& Socio-economic divisions parallel with ethnic divisions
\end{tabular}

Note: The patterns highlighted are the result of the study of four cities: Berlin, Belfast, Jerusalem, and Beirut. Source: Caner and Bölen (2016). 


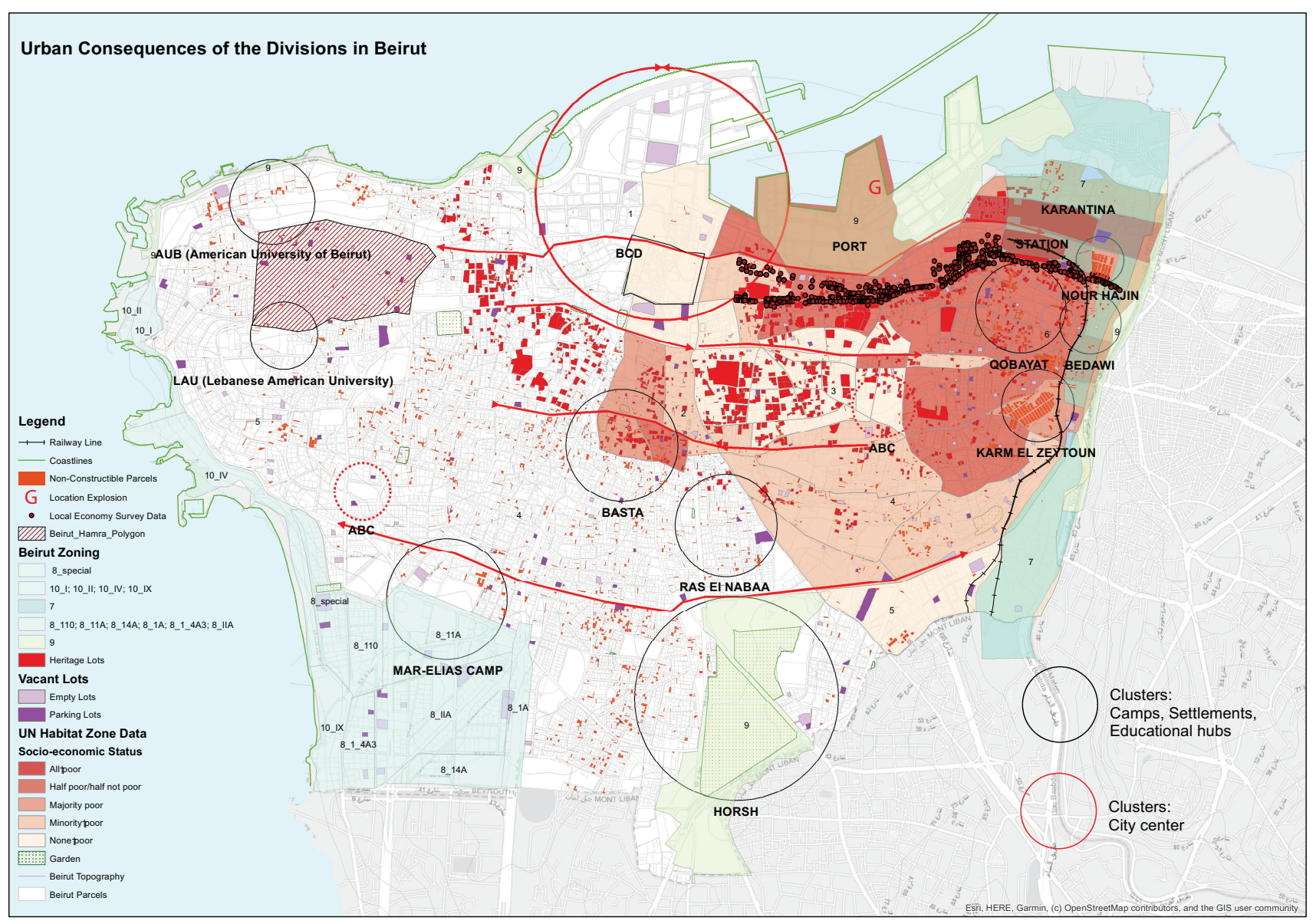

Figure 2. Urban consequences of the divisions in Beirut.

\subsection{Uninformed Planning Decisions}

Before, during, and after the Lebanese Civil War (1975-1990), the spatial organization of Beirut has strengthened the unfolding of diverging ideologies (Yassin, 2008). Since the civil war, many schemes and reconstruction plans have been proposed; however, the problems that faced the implementation of those schemes remain the same. They are most evident in the rehabilitation of the center (Beirut Central District [BCD]) that symbolizes and mitigates Lebanon's postwar shortcomings: inequality, corruption, and segregation (Larkin, 2010a). With unclear state constitution and outsourced public undertaking, urban planning has become a dispute between religious-political organizations and profitseeking developers (Bou Akar, 2018).

According to Verdeil (2012), there are four periods of reconstruction of Beirut and its suburbs: (1) the first downtown reconstruction project in 1977 following the two-year war; (2) the second downtown Beirut reconstruction attempt in 1982-1983, which was never adopted; (3) the reconstruction of the BCD which was entrusted to Solidere since 1991; and (4) the case of the post-war reconstruction of Haret Hreik (Waad Project), in 2006. Moreover, the post-war reconstruction phase has been marked by two national plans: the National Emergency Reconstruction Plan, orchestrated for the first five years of reconstruction, and Plan Horizon 2000, complemented later by Plan Horizon in 2005. The two plans were managed by the Council for Development and Reconstruction, established in 1977 as a public central management organism for all reconstruction works. More than 100 projects were planned over 15 sectors, essentially financed by foreign and internal loans (United Nations Human Settlements Programme, 2003).

The above-mentioned schemes were never about a complete and sustainable planning solution for the totality of the Lebanese territory; instead, they favored selective urbanism and divisions, building on quick solutions from a developer's perspective. I would extend this argument to say that the reconstruction schemes were almost treating the territory as an informal space, secluded and isolated from all contingencies. Avni and Yiftachel (2014), in their chapter on "gray spaces" in divided cities, suggest that there are several typical stages of urban policy responses to the emergence of informality within the process of "gray spacing" in the sense of informal development where ignoring, neglecting, limiting, and whitening selectively can be described as the toolkit of managing the unwanted/irremovable 
in today's urban regions and economies. By ignoring the needs of citizens, neglecting the real urban issues, limiting interventions, and whitening selectively certain areas such as Solidere, the state has prolonged turning a blind eye to what is really needed, proposed underdeveloped schemes and policies, violently limited the areas of intervention, and pushed for anesthetization, privatization, and gentrification. When the numerous systems that are essential for the city functioning fail and stop being efficient, they result in the emergence of negative economic, social, and environmental impact. In addition to the deficit in government provision of services because of weak management practices urban informal systems emerge, complementing or competing with formal services in order to meet the everyday needs of urban residents (Farajalla et al., 2017). As an example, the development of the BCD promised a social recovery through economic renewal (Fricke, 2005); instead, it was conceived in a complete isolation, enclosing the city center by a limited ring road and a connector to the highway leading to the airport. By creating a vacuum within the city, a space devoid of social matter, it managed to disconnect the city from its center and displaced families, owners, and tenants (Larkin, 2010a; Yahya, 2004). More critically, the sectarianized and enclaved city continued to be spatially divided across the war-induced sectarian lines, indicating a failure to return to normalcy (Yassin, 2012). War-damaged cities also force citizens to explore urban antagonism and tolerance and to see how designers, planners, and policymakers can contribute practically to the alleviation of racial and social segregation (Calame \& Charlesworth, 2009).

On the other hand, many of the proposed projects by professionals invited to participate in the post-war reconstruction process seemed unrealistic (Charlesworth, 2007). They tend to propose quick interventions that are of interest to international donors, investors, and developers, which in some cases hastened the fundamental reasons of conflict due to either their lack of expertise working in split political and physical landscapes or the lack of interest in finding real solutions for serious urban issues. Functionalist planning and zoning as a way to deal with sectarianism (Bollens, 2012) and the obsession for building iconic landmarks is put upfront by local and foreign architects who assumed that the systematic rebuilding of the historic core of the devasted city will restore the city, almost immediately, to its prewar identity and community spirit. Such positions frequently overlooked the fact that the surrounding urban fabric, infrastructure, and social fabric are all in shambles. Most of the time, leftover areas, transition zones, and boundaries of conflict, or the often abandoned and neglected peripheries of the central zones of cities were ignored (Charlesworth, 2007). Despite some attempts to redirect Beirut towards a wider Lebanese state building project and ever-changing geopolitics of the region (Larkin, 2010b), it was clear that some pillar planning terminologies such as connectivity, mobility, middle class, sustainability, heritage preservation, social inclusion, public space, environment, and demography were fated to become obsolete.

In post-conflict cities, political opportunities may arise fueled by the attractiveness of the concept of city reconstruction. Stemming from the various dynamics behind the reconsolidation of a national identity and economic recovery, ambitious political endeavors, and longterm agenda could be deceiving (Charlesworth, 2007). Since the port blast in August 2020, some real awareness started to emerge regarding the state of the city, its failed urban heritage, and its vague future.

\section{Beirut Urban Declaration: A Case Study}

The BUD initiative was launched on August 10th, 2020, with the participation of the Order of Engineers and Architects in Beirut, the schools of architecture in Lebanon, the Chadirji Foundation for Architecture and Society, the Architects Association, and the Urban Planning Association. This initiative was a response to the devastating explosion of the Beirut Port on August 4th, 2020 (Order of Engineers and Architects, 2021). It reviews a set of ideas that would constitute a starting point for work to formulate an integrated vision for the reconstruction of the affected areas. It proposes a national vision for reconstruction, heritage rehabilitation, protection of the social fabric, distinguished urban identity in affected areas, and the reformulation of the port relationship within its urban context. The declaration is an intellectual and cultural endeavor that contributes to the formulation of a comprehensive vision in form of ideas and proposals of the reformation of the city. The compiled report aims at addressing the challenges of depopulating the city from its residents and demography change by offering officials and institutions proposals and quick practical and operational options. By proposing a comprehensive view of socioeconomic and urban aspects dealing with the damaged area as an urban fabric fully integrated with its surroundings, the declaration highlights the course of action and the role that the OEA could play in visualizing the rehabilitation of the impacted region in collaboration with universities.

The BUD emphasizes preserving the heritage urban fabric, which consists of their general fabric and the constituent units of this tissue, as a site in which individuals' socio-economic behavior is practiced. Considering the heritage character of the affected area, it will be crucial to determine the paths between urgent, medium-, and long-term to eventually establish an observatory. Finally, the need to initiate appropriate policies and a reconstruction management must go through devising mechanisms that can guarantee wide participation of the society and specialists. Research focusing on the study of the urban typo-morphology of the area and connectivity of the Medawar/Karantina-Rmeil (Aouad \& Kaloustian, 2021) presented during the BUD conference back in April 2021 (see Figure 3), recognizes the following: 


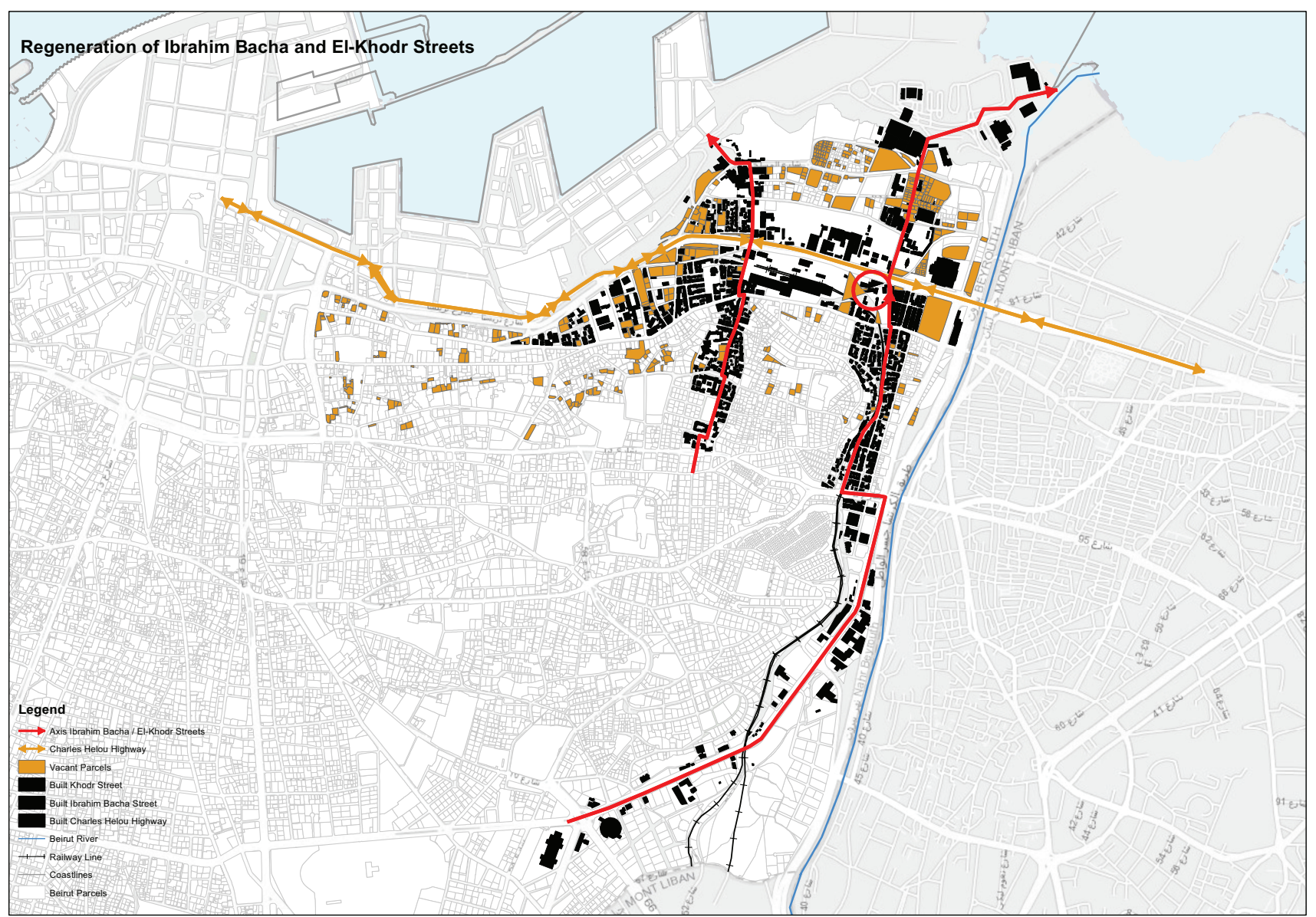

Figure 3. BUD: Axe 3. The regeneration of Ibrahim Bacha and El-Khodr Streets is represented in red. Source: Author's work based on the Order of Engineers and Architects (2021).

Sustainable urban planning can be partly achieved through small scale interventions such as the reactivation of vacant lots and non-constructible parcels through connected paths and the re-use of heritage buildings.... Reactivating public life, through the elaboration of neighborhood scale urban strategies and engaging residents in improving their built environment, should be a priority. (Aouad \& Kaloustian, 2021, p. 9)

Although the roadmap of the declaration was paved with good intentions, it could be argued that the methods used still fundamentally stem from the traditional planning school. Having played a major role in the development of Axe 3 (Figure 4) that led to the final formulation of the BUD, one must admit that the BUD was far from serious field-work surveys and accurate social assessment of the devastated areas and their inhabitants. This part was at times compensated by work from NGOs but never really compiled and overlayered to the academic work the BUD was preparing. Collaboration at early stage with field groups/NGOs was required and could have been crucial in the elaboration of a more in depth understanding of the needs of neighborhoods. One of the downsides of the report is that it does not effectively acknowledge the new reality of divisions highlighted above (Figure 2). Although it was clear from the beginning that no masterplan for the city of Beirut would be developed to avoid falling in the trap of traditional planning, it was quickly obvious that the lack of field data and close encounters with inhabitants would lead to a generic solution far from the imposed realities of the urban situation.

Local stakeholders are uncritically adopting such initiatives, exploring their ambitions, measures, as well as the impediment of their strategies. Any sustainable city strategy that disregards those differences and diversities have and will introduce an urban entrepreneurship that reinforces exclusion and welcomes gentrification rather than disintegrating social and ethnical boundaries.

\section{Scaling Down}

While the BUD in most of its approach still clings to the idea of the city as a unified physical model, a top-down approach in disguise undermining the differences that subsist between individuals, it is time to shift the focus from this broader understanding of the city to an approach centered around navigating social, infrastructural, economic, and environmental complexity (Myerson, 2016): This is called scaling down. It could 


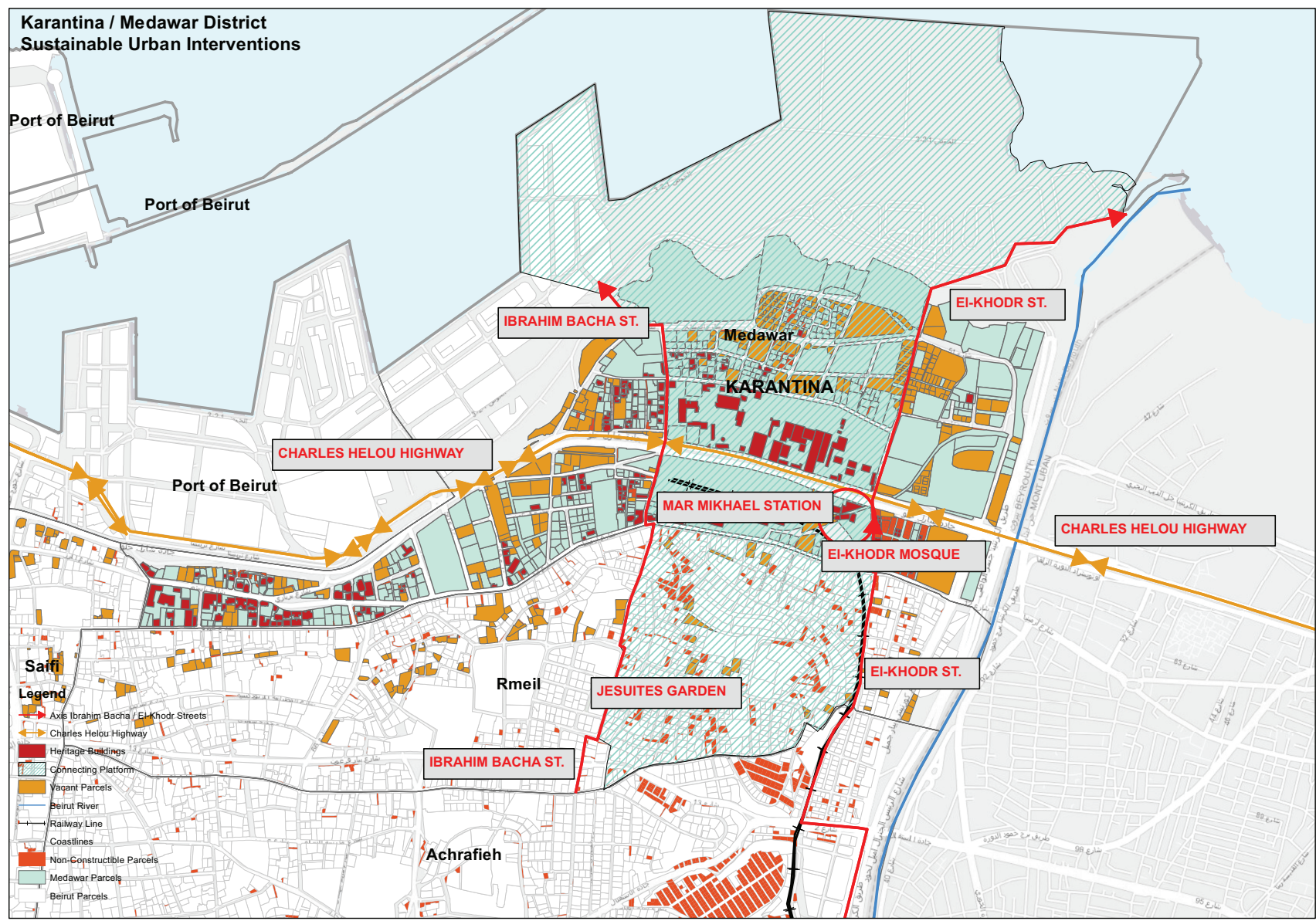

Figure 4. BUD. Study of the urban typo-morphology of the area and its connectivity to neighboring parts: Case study of the areas of Medawar/Karantina-Rmeil in Municipal Beirut. Source: Author's work based on and map from Aouad and Kaloustian (2021, p. 10).

be argued that it is still too soon to completely ditch traditional planning tools at the expense of more creative and innovative ones; however, imposing fixed master plans in post-conflict situations could prove too rigid and superficial of an approach and need to be re-assessed. While the BUD has set itself a goal from the beginning that a master plan would not be the main objective, all actions and recommendations still rely heavily on traditional planning tools moving away from sustainability, long-term economic viability, and improved social cohesion. With the recent rise of people-centered approaches focusing on specific human needs and experiences, the BUD privileged the urban level dismissing that there is a fragmentation and breakdown of the urban system where the center no longer holds. In seeking post-conflict reconciliation and building horizontal linkages that support citizenship, micro-scale, street level interventions with an incremental approach may be a more appropriate frame of reference and could present better opportunities for mixing rather than being districts of fear and sectarian retrenchment (Bollens, 2012). For the residents of Beirut, this kind of urban planning could hold promise where a new spatial order could bring a peaceful future (Bou Akar, 2018).

\subsection{The Neighborhood}

A neighbourhood is a collection of individuals who share services and some level of cohesion in a geographically bounded place. Among three keywords defining neighbourhoods-people, place, and cohesionplace is the most noticeable term to distinguish neighbourhoods from other terms like community (Park \& Rogers, 2015). Waves of migration and displacement from and towards Beirut have played a crucial role in the city's shifting demographics, sense of diversity, and urban transformation (Faour, 1991). Pre-civil war migration from rural areas, the Lebanese civil war, the Armenian refugees' camps, the recent Syrian crisis, the current post-war/blast era, and a continuous change in land-use, character, and identity have shuffled the demographic and reshaped the city by building clusters within and around it and favoring sectarian peripheral centralities and isolating neighborhoods. A planning workshop organized in 2007 by the American University of Beirut, focusing on the Mar Mikhael neighborhood (Ghaddar, 2020), has shown that many of these events carry direct effects on the current status of neighborhoods in Beirut: Evictions, displacements, 
abandonments, re-appropriation of public space, demographic changes and degradation of residual spaces, changes in economic activity, and deterioration of old businesses have impacted decisions regarding the built environment, provision of economic opportunities, and delivery of public services.

In divided cities such as Beirut, it is essential that the social and economic dynamics behind segregation of neighborhoods be understood (Grigsby et al., 1987), since they have a direct effect on processing conversions in quarters and neighborhood characteristics and spatial patterns (Megbolugbe et al., 1996). Grigsby's realism in understanding what policies can really do as opposed to what individuals wish they could do is reflected in his affirmation to characterize neighborhood change in terms of occupants rather than the physical condition of the stock (Megbolugbe et al., 1996). In one of the axes developed by the BUD, the neighborhoods along the two streets of El-Khodr and Ibrahim Bacha (Figure 4) were defined not because they belong to the same districts, but rather because they are organized along two historical commercial strips that have been in decay for the past few years. El-Khodr Street still has traces of the old railway tracks and denotates a strong socio-economic cohesion along its edges through the commercial shops and income level of its inhabitants. By highlighting this strip, analyzing the typo-morphology of its built fabric, and classifying the urban elements that are integrate parts of the city, this approach recognizes the existing urban forms supplemented by existing or desired functions in the neighborhood (Order of Engineers and Architects, 2021). However, a participatory mindset is painfully missing from this approach, making those design methods seem almost obsolete. Collaborative methods and a deeper investigation of the real needs of the population, highlighting the challenging and complex problems that people are facing on daily basis, could lead to a rather design-infused approach (Myerson, 2016).

\subsection{Community-Driven Neighborhood Planning in the Divided City of Beirut}

Neighbourhood-based planning is more reactive to local influences since problems are small enough to effectively engage the residents and local stakeholders (Park $\&$ Rogers, 2015). One of the main impediments to the enactment of an alternative vision for the neighborhood is the absence of effective planning tools in Lebanon's planning regulations. Beirut neighborhoods play many different roles in the city and attract divergent and disparate communities. Prone to speculative developments and a sense of exclusiveness, Beirut's urbanization is highly random and developer-oriented, lacking an institutional framework that would be adequate to develop a neighborhood planning approach based on community participation, carrying capacity, safety, and environmental quality. A strategic intervention at the scale of the neighborhood should be led by authorized local commu- nity organizations, known as qualifying bodies (neighborhood planning bodies), and requires the initiation of a bottom-up, inclusive, and people-centered recovery process. Through the transformation of structures of social life from top-down to bottom-up, the institutionalization of the existing structures might facilitate accommodative and transformative behavior, coexisting with uncivil practices and institutions (Mady \& Chettiparamb, 2016).

Five recommendations are proposed so that community-driven neighborhood planning leads to transformative change acknowledging the divided nature of the society. It is worth noting that the article is not focused on "how" these recommendations are unraveled but more on "what" they consist of in terms of methods. Through inclusive neighborhood planning, broadening the opportunities for individuals across neighborhoods, using performance-based planning, linking the most disadvantaged neighborhoods, and promoting and protecting the collective public sphere, a shift to reverse could be achieved, leading to a better understanding of the social fabric, hence creating with the people rather than for them (Myerson, 2016).

First, through land-use regulations that facilitate the building of new housing, engaging in equity planning that addresses underlying root issues, neighborhoods could become more inclusive, livable, equal, and affordable. The BUD (Order of Engineers and Architects, 2021) acknowledges that this point constitutes an important factor in developing a dynamic overview that addresses the history of all existing buildings since it represents the culture of Lebanese society; in addition to the formulation of building regulation to reflect the history of the society and its relationship to the public and private scales of the city, both have failed to acknowledge that prior to the blast the city council had always been very politicized and represented almost all the political parties of the city and thus very few decisions were taken in the right direction and without consensus. Moreover, and for the past several decades, no revision of the city's urban master plan has been proposed despite the present sanitary and cultural emergencies the city is facing. In light of these setbacks, in a city that has scaled down its governance to smaller divisions, a proposal has been currently inapplicable and already rejected by several politicians to avoid any sectarian divisions (Mady \& Chettiparamb, 2016). One would argue that relying on the existing political structure to implement such revisions could be almost impossible, hence the shift to a smaller scale intervention, bottom-up community approach that would delegate powers, even temporarily, to neighborhoods within municipalities by betting on civil society engagement to voice concerns and protect from the constant government vetoes. By de-institutionalizing the process and disengaging from formal structures, transformative action could be unleashed.

Second, in broadening opportunities for individuals across neighborhoods lacking access to high-quality 
education and training, along with empowering marginalized groups, community-driven neighborhood planning implies the recognition that anyone can make a difference in their life as well as that of others. In Beirut, the government does not and cannot allocate sufficient resources to efficiently support programs aiming at poverty reduction. In this context, civil society organizations, including a wide range of organizations, may take over this responsibility and promote and support self-help institutions, volunteer organizations, and groups of interest to fight poverty. However, civil society cannot operate in a vacuum or in isolation; as a result, there must be a network and a connection with both government institutions, the private sector, and international organizations. The BUD mentions in its report that the socio-economic challenges stemming from the urban transformations of the city are mainly based on the local community transformations, which will eventually organize the needed services of the local community in order to formulate a clear methodology that helps structure the social needs. The BUD report (Order of Engineers and Architects, 2021) includes a sociological study that has covered several individuals from different groups and sectors in the region, enquiring about people's needs, their view of planned or observed projects, their diagnosis of the most pressing issues, and their future speculations. However, as mentioned previously, the study has failed to acknowledge the current divisions that these neighborhoods are going through resulting in identity-based breaches; it rather enhances those breaches by focusing on the current state of these neighborhoods. The proposed recommendations such as considering social culture as a priority, establishing business incubators, and securing education and health have barely touched base with groups or NGOs working on the ground. Rather than building a common database that would become a foundation for future studies, it has resulted in fractions of data disseminated amongst groups making it very difficult for all involved parties to assess the reality of the situation on the ground.

Third, by using performance-based planning parameters such as performance zoning, neighborhood sustainability assessment tools (Sharifi \& Murayama, 2014), flexible zoning, outcome-oriented planning, and effectbased planning (Baker et al., 2006), the emphasis is put on short-term tactical interventions. A recent report by Chetwyn (2018) defines three stages for the development of neighborhood plan roadmap using performancebased planning that will elaborate a planning policy for a neighborhood area to guide future development: first, designating the neighborhood area and the neighborhood forum while building an evidence base and engaging publicly; second, drafting the plan while meeting the basic conditions (national policy, sustainable development, conformity with strategic policies, and other obligations) and preparing pre-submission consultations; and third, bringing the plan into force by submitting it to local planning authorities, publicizing it, examining it independently, and assessing it for lessons learned. Creating a neighborhood plan is about making efficient use of land and may include a vision, goals, planning policies, and suggestions for improving the area by adding new facilities or designating key sites for specific types of development. It should acknowledge social, economic, and environmental issues such as housing, employment, design, heritage, and transport or it may focus on just one or two issues (Chetwyn, 2018).

Fourth, in striving to enhance people's physical and psychological assets and building on what individuals and communities have to offer, it will be significant to negotiate linking the most disadvantaged neighborhoods with places of opportunity through better transport connections between the locations of jobs and residential locations using flexible and porous urban forms. The researcher's contribution within the BUD dealt with the pillar of architectural urban transformations and socio-economic changes based on which service data could be used by the local community and which must be studied to form a clear methodology for developing the city's structure. This condition is reflected in this study through the reconnection of Mar Mikhael area with Karantina through the reactivation of two main roads that historically represent this relationship with the areas before the Charles El Helou highway, namely Ibrahim Bacha Street and Al Khodor Street (Figure 4). However, in that case, the concept of mobility should have been introduced, by working with experts in that discipline and co-designing and prototyping new means of transportation. In an effort to bring awareness to bottom-up planning within the neighborhood of Badawi, at the Eastern edge of Beirut city, one venture is aiming to do so: Through the collaboration of KU Leuven, the Lebanese Academy of Fine Arts, and the Institute of Environmental Studies and Research at the Lebanese American University, an e-bike and low-tech energy device do-it-yourself workshop will be launched. The workshop, launched on the 11th of November 2021, has kickstarted a larger and longer project in Lebanon aimed at creating a sustainable citizen-based network or infrastructure. Apart from the practical work, there were talks, lectures, guest teachers, and discussions on how a participative society works and what are the obstacles and challenges for enabling micro-scale governance structures tackling the question of whether a bottom-up urbanism is possible in Beirut.

Fifth, for the seed of urban stability and co-existence to grow, the public sphere in both physical and institutional forms should encompass and respond to all competing identity groups in the city by promoting and protecting the collective public sphere. Physically, planners should revitalize and redevelop public spaces, historic areas, and other urban public assets as places of interaction and neutrality that promote healthy intergroup and interpersonal life. Instead of focusing on the inflammatory choice between segregation versus integration of residential areas, concentration on improving 
public spaces may offer another approach less difficult to achieve for political reasons. As a result, there is a push for mixed public spaces rather than mixed neighborhoods. The goal is to enable increased crossethnic mingling in non-hostile, non-polarizing public environments rather than trying to adopt the more inflammatory approach of having different ethnicities cohabitat residentially (Bollens, 2012). However, this can be better achieved by allowing for better communication and negotiation based on a common understanding of shared values through a consensus-oriented process (Mady \& Chettiparamb, 2016) that could eventually mitigate certain small divisions within a specific neighborhood leading to a rich and diverse set of micro-practices in the hope of achieving a better quality of life.

\section{Conclusion}

This article has explored neighborhood planning in deeply divided cities/societies in Beirut. It has been suggested that while clear dividing lines have been officially removed after the civil war, it is now a reality that the climate of divide created by these boundaries is still heavily anchored in the mental maps of inhabitants. Whether through psychological fractures, sectarian and racial turbulence, or political obstacles, profound insights into the fear, separation, violence, and alienation run within the city of Beirut. Under the circumstances, and more specifically following the August 4th tragic blast, it has been argued that some unique and non-negligible functional, structural, socio-economic, and physical consequences have emerged and that it would be more useful to shift planning from the traditional schemes and reconstruction plans that have been proposed so far, since the civil war, to a more neighborhood-centered sustainable approach. Since the blast, there has been considerable interest in bottom-up initiatives with planning centered more towards civil society-led initiatives. While the question of how planners might work with such initiatives is important, it has been argued that the question of how devastated neighborhoods should get organized, almost autonomously, to rebuild what was lost and enhance their quality of life is equally important and must be reasonably answered. Building upon the divided cities and neighborhood planning literature and critically dissecting the action plan of the BUD as a potentially innovative approach to city planning, five recommendations have been suggested that may need to be present individually or in combination in bottom-up initiatives attempting to bridge deep differences. These recommendations involve inclusive neighborhood planning, broadening the opportunities for individuals across neighborhoods, using performance-based planning, linking the most disadvantaged neighborhoods, and promoting and protecting the collective public sphere. It has been argued that through the implementation of these tools, a shift to reverse could be achieved, leading to a better understanding of the social fabric, hence creating with the people rather than for the people. The presence of these five tools has been demonstrated in the case study of the BUD showing how some of the aspects of the report have responded effectively to the bottom-up approach for neighborhood planning by using strategies that encompass the five ways identified earlier. However, it has also identified its weaknesses as far as its lack of collaboration with civil society and NGOs, the political agenda setbacks related to previous master plans, the concepts of mobility, and the deep understanding of the social and physical divide that exist within its realm. While these initiatives are not, by themselves, the solution to the conflicting divisions within the city and society, they can certainly contribute to an agenda that seeks to cut-across narrow sectarianism to confront, exchange, and acknowledge a wider program. At the very least, they provide conceptual and experiential resources useful in developing a flexible framework for the sustainable development of the devastated neighborhoods allowing field professionals such as architects, planners, urban designers, and landscape architects to engage in the processes of social, economic, and physical reconstruction shifting their focus from the city scale traditional planning tools to local planning tools at a neighborhood scale. Hence, this article has called for a revamping and undertaking of the sustainable city model in which intra-urban inequalities, divisions, and civic disinterest are the focal point rather than the understanding of the specificities of each neighborhood and its users, including the enactment of social differences, not only as an urban development strategy, but also as a human right.

\section{Conflict of Interests}

The author declares no conflict of interests.

\section{References}

Aouad, D., \& Kaloustian, N. (2021). Sustainable Beirut city planning post August 2020 port of Beirut blast: Case study of Karantina in Medawar district. Sustainability, 13(11), Article 6442. https://doi.org/10.3390/ su13116442

Avni, N., \& Yiftachel, O. (2014). The new divided city? Planning and "gray space" between Global NorthWest and South-East. In S. Parnell \& S. Oldfield (Eds.), The Routledge handbook on cities of the Global South (pp. 487-503). Routledge.

Baker, D. C., Sipe, N. G., \& Gleeson, B. J. (2006). Performance-based planning: Perspectives from the United States, Australia, and New Zealand. Journal of Planning Education and Research, 25(4), 396-409. https://doi.org/10.1177/0739456X05283450

Bollens, S. A. (2007). Urban governance at the nationalist divide: Coping with group-based claims. Journal of Urban Affairs, 29(3), 229-253.

Bollens, S. A. (2012). City and soul in divided societies. Routledge. 
Bou Akar, H. (2018). For the war yet to come: Planning Beirut's frontiers. Stanford University Press.

Calame, J., \& Charlesworth, E. R. (2009). Divided cities: Belfast, Beirut, Jerusalem, Mostar, and Nicosia. University of Pennsylvania Press.

Caner, G., \& Bölen, F. (2016). Urban planning approaches in divided cities. A/Z ITU Journal of the Faculty of Architecture, 13(1), 139-156. https://doi.org/ 10.5505/itujfa.2016.74936

Charlesworth, E. (2007). Architects without frontiers. Routledge.

Chetwyn, D. (2018). Neighborhood plans roadmap: A step-by-step guide (2018 edition). Locality.

Davie, M. F. (1994). Demarcation lines in contemporary Beirut. In C. H. Schofield \& R. N. Schofield (Eds.), The Middle East and North Africa (pp. 35-58). Routledge.

Faour, M. (1991). The demography of Lebanon: A reappraisal. Middle Eastern Studies, 27(4), 631-641. https://doi.org/10.1080/00263209108700881

Farajalla, N., Badran, A., El Baba, J. T., Choueiri, Y., El Hajj, R., Fawaz, M., \& Chalak, A. (2017). The role of informal systems in urban sustainability and resilience: A review. Issam Fares Institute for Public Policy and International Affairs. https://www.aub.edu.lb/ifi/ Documents/publications/research_reports/20162017/20170706_informal_systems.pdf

Fregonese, S. (2009). The urbicide of Beirut? Geopolitics and the built environment in the Lebanese civil war (1975-1976). Political Geography, 28(5), 309-318. https://doi.org/10.1016/j.polgeo.2009.07.005

Fricke, A. (2005). Forever nearing the finish line: Heritage policy and the problem of memory in postwar Beirut. International Journal of Cultural Property, 12(2), 163-181. https://doi.org/10.1017/ S0940739105050150

Ghaddar, A. M. (2020). Introducing performance-based planning in context of rapid urban transformations, the case of Mar Mikhael, Beirut (Lebanon) [Master thesis, American University of Beirut]. AUB ScholarWorks. http://hdl.handle.net/10938/21935

Grigsby, W., Baratz, M., Galster, G., \& Maclennan, D. (1987). The dynamics of neighborhood change and decline. Department of City and Regional Planning, University of Pennsylvannia.

Larkin, C. (2010a). Beyond the war? The Lebanese postmemory experience. International Journal of Middle East Studies, 42(4), 615-635. https://doi.org/ $10.1017 / \mathrm{s} 002074381000084 x$

Larkin, C. (2010b). Remaking Beirut: Contesting memory, space, and the urban imaginary of Lebanese youth. City \& Community, 9(4), 414-442. https://doi.org/ 10.1111/j.1540-6040.2010.01346.x

Leclair-Paquet, B. (2013). Beirut divided: The potential of urban design in reuniting a culturally divided city (DPU Working Paper No. 153). Development Planning Unit, University College London.

Mady, C., \& Chettiparamb, A. (2016). Planning in the face of "deep divisions": A view from Beirut, Lebanon.
Planning Theory, 16(3), 296-317. https://doi.org/ $10.1177 / 1473095216639087$

Martínez, J. (2009). The use of GIS and indicators to monitor intra-urban inequalities. A case study in Rosario, Argentina. Habitat International, 33, 387-396. https://doi.org/10.1016/j.habitatint.2008. 12.003

Megbolugbe, I. F., Hoek-Smit, M. C., \& Linneman, P. D. (1996). Understanding neighbourhood dynamics: A review of the contributions of William G. Grigsby. Urban Studies, 33(10), 1779-1795. https://doi.org/ 10.1080/0042098966367

Myerson, J. (2016). Scaling down: Why designers need to reverse their thinking. She Ji: The Journal of Design, Economics, and Innovation, 2(4), 288-299. https:// doi.org/10.1016/J.SHEJI.2017.06.001

OECD. (2018). Divided cities: Understanding intra-urban inequalities. https://doi.org/10.1787/9789264300 385-en

Order of Engineers and Architects. (2020). Beirut port explosion of August 4, 2020: Buildings final structural assessment report.

Order of Engineers and Architects. (2021). Beirut Urban Declaration for the reconstruction of the neighborhood hit by the August 4th explosion.

Park, Y., \& Rogers, G. O. (2015). Neighborhood planning theory, guidelines, and research: Can area, population, and boundary guide conceptual framing? Journal of Planning Literature, 30(1), 18-36.

Sharifi, A., \& Murayama, A. (2014). Neighborhood sustainability assessment in action: Cross-evaluation of three assessment systems and their cases from the US, the UK, and Japan. Building and Environment, 72, 243-258.

Silver, H. (2010). Divided cities in the Middle East. City \& Community, 9(4), 345-357. https://doi.org/10.1111/ j.1540-6040.2010.01348.x

United Nations Human Settlements Programme. (2003). Part IV: Summary of case studies. In The challenge of slums: Global report on human settlements 2003 (pp. 195-228). UN-Habitat. https://unhabitat.org/sites/ default/files/download-manager-files/The\%20 Challenge\%20of\%20Slums\%20-\%20Global\%20 Report\%20on\%20Human\%20Settlements\% 202003.pdf

van Kempen, R. (2007). Divided cities in the 21st century: Challenging the importance of globalisation. Journal of Housing and the Built Environment, 22(1), 13-31. http://www.jstor.org/stable/41107366

Verdeil, É. (2012). The reconstruction between urban planning policies and cultures: Beirut-based reflections. In The uniqueness of experience: Workshop on the reconstruction of the southern suburb of Beirut after the Israeli aggression in 2006 (pp. 88-101). Waad.

Yahya, M. (2004, July 7-11). Let the dead be dead: Memory and the post-civil war reconstruction in Beirut [Paper presentation]. Center of Contemporary Cul- 
ture of Barcelona's Symposium "Urban Traumas: The City and Disasters," Barcelona, Spain. http://www. cccb.org/rcs_gene/let_the_dead_be_dead.pdf

Yassin, N. (2008). The urban dimension of civil conflict and violence: $A$ study on the relationship between the city, conflict and violence in Beirut [Doctoral dissertation, University College London]. UCL Discovery. https://discovery.ucl.ac.uk/id/eprint/14303

Yassin, N. (2012). Beirut. Cities, 29(1), 64-73. https:// doi.org/10.1016/j.cities.2011.02.001

\section{About the Author}

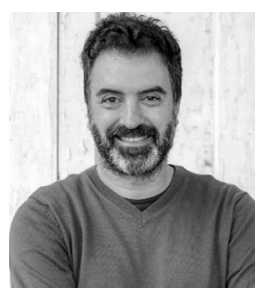

David Aouad is assistant professor of practice at the Lebanese American University, Lebanon. He is director of the Institute of Environmental Studies and Research and founding partner of DAJH Architects. Aouad's research agenda revolves mainly around topics of critical importance within the public realm such as residual spaces, disconnected urban fragments, urban heat islands, rural regeneration, urban crisis management, and divisions within the city. He is working on a series of interconnected research projects in Beirut on urban mobility, habitability, and the urban project. His writings on non-constructible parcels, urban heat islands, education, and sustainable planning have been published in Climate, Sustainability, Mobility and Design, and in many edited collections on architectural societal challenges, sustainability, and climate. 